\title{
DESAFIOS DA FORMAÇÃO SUPERIOR INDÍGENA NA AMAZÔNIA BRASILEIRA: REFLEXÕES A PARTIR DE UMA ETNOGRAFIA DO TIPO ESCOLAR
}

\author{
Genivaldo Frois Scaramuzza ${ }^{1}$ \\ http://orcid.org/0000-0003-3738-9905 \\ Maria Isabel Alonso Alves ${ }^{2}$ \\ http://orcid.org/0000-0002-2960-1200 \\ Simone Alves Scaramuzza ${ }^{3}$ \\ https://orcid.org/0000-0002-1434-4694
}

RESUMO: O objetivo central deste texto é problematizar os desafios da formação de professores indígenas na Universidade Federal de Rondônia a partir do pressuposto conceitual da interculturalidade. Analisa a partir de um fragmento etnográfico escolar as representações de docentes indígenas sobre identidades em sua relação com a produção de materiais didáticos. Em termos metodológicos, o estudo foi construído a partir de uma Etnografia do tipo escolar (ANDRÉ, 2005). O estudo mostrou a necessidade de produzir materiais didáticos diferenciados para os povos indígenas, de modo a operar uma matriz de conhecimento intercultural nas escolas das aldeias, assegurando as identidades e saberes indígenas em diálogo com os conhecimentos de matrizes coloniais.

PALAVRAS-CHAVE: identidades, formação indígena, materiais didáticos, interculturalidade.

\section{CHALLENGES OF INDIGENOUS HIGHER EDUCATION IN BRAZILIAN AMAZON: REFLECTIONS FROM A SCHOOL TYPE ETHNOGRAPHY}

ABSTRACT: The main objective of this text is to discuss the challenges of indigenous

\footnotetext{
${ }^{1}$ Doutor em Educação, Professor da Universidade Federal de Rondônia - UNIR, Ji-Paraná-RO, Brasil. scaramuzza1@gmail.com

${ }^{2}$ Doutora em Educação, Professora da Universidade Federal do Amazonas - UFAM, Humaitá -AM, Brasil. profamariaisabel@ufam.edu.br

${ }^{3}$ Mestre em Educação, Supervisora Escolar - SEMED/JP, Ji-Paraná - RO, Brasil. simonescaramuzza23@ gmail.com
} 
teachers formation at the University Federal in Rondônia based on the conceptual assumption of interculturality. It analyzes, froman ethnographic fragment of school, the representations of indigenous teachers about identities in their relationship with the production of teaching materials resources. In methodological terms, the study was built from an ethnography of the school type (ANDRÉ, 2005). The study showed the need to produce different teaching materials for indigenous peoples, in order to operate an intercultural knowledge matrix in village schools, ensuring indigenous identities and knowledge in dialogue with the knowledge of colonial matrices.

KEYWORDS: identities, indigenous formation, teaching materials, interculturality.

\section{DESAFÍOS DE LA FORMACIÓN SUPERIOR INDÍGENA EN LA AMAZONIA BRASILEÑA: REFLEXIONES A PARTIR DE UNA ETNOGRAFÍA DE TIPO ESCOLAR}

RESUMEN: El objetivo central de este texto es problematizar los desafíos de la formación de profesores indígenas en la Universidad Federal de Rondônia, partiendo del postulado conceptual de la interculturalidad. Analiza desde un fragmento etnográfico escolar las representaciones de docentes indígenas sobre identidades en relación con la producción de materiales didácticos. En términos metodológicos, el estudio fue construido a partir de una Etnografía de tipo escolar (ANDRÉ, 2005). Este trabajo develó la necesidad de producir materiales didácticos de carácter diferencial para los pueblos indígenas, con el fin de ejecutar una matriz de conocimiento intercultural en las escuelas de las comunidades, afianzando las identidades y los saberes indígenas en dialogo con los conocimientos de matrices coloniales.

PALABRAS CLAVE: Identidades, formación indígena, materiales didácticos, interculturalidad.

\section{Considerações Iniciais}

A educação intercultural traduzida em práticas escolares, bem como, em materiais didáticos específicos, tem se constituído em um amplo desafio para os povos indígenas. As práticas escolares utilizadas junto a essas populações desde o período colonial, em muitos casos, estiveram a serviço dos conhecimentos advindos da sociedade ocidental por meio de modelos educacionais expressos pela colonialidade do saber/poder (CUSICANQUI, 2010; QUIJANO, 2005). 
Entendemos que uma postura pedagógica centrada nos processos de ressignificação cultural, onde os conhecimentos "outros" dos sujeitos que fogem às perspectivas do pensamento moderno, homogeneizador, tendem a promover uma decolonialidade na escola, contribuindo para a ampliação da educação intercultural. Seguindo Castro-Gomez (2007) e Grosfoguel (2007), é pertinente mencionar que o pensamento decolonial também invoca uma epistemologia, um sujeito e/ou um projeto político capaz de questionar os modelos eurocêntricos do conhecimento e suas diversas formas de atuação.

Cabe destacar que as escolas indígenas têm procurado modificar essa visão eurocêntrica de dominação e aculturação, todavia, muito ainda há de se fazer para que se conquiste a autonomia indígena em seus espaços de escolarização, principalmente, a partir da criação de alternativas didáticas e pedagógicas capazes de fazer emergir a decolonialidade como um exercício de interculturalidade (LANDER, 2005; SECCHI, 2007).

Embora, historicamente seja possível falar em diversas práticas de extermínio físico e de invisibilidade do conhecimento indígena, muitos avanços foram sendo construídos principalmente a partir da Constituição Federal de 1988, seguida posteriormente da Lei de Diretrizes e Bases da Educação (LDB/96) e outras Resoluções e Referenciais que institucionalizam as premissas legais para a Educação Escolar Indígena no Brasil, levando em conta as diversidades étnicas e culturais dessas populações (NASCIMENTO; URQUIZA AGUILERA, 2010).

As universidades também foram inseridas nesta nova temática emergente que envolve a formação de professores/as indígenas para atuarem nas escolas das aldeias na perspectiva da interculturalidade (ALVES, 2014; NEVES, 2009).

Para se estabelecer esta relação de troca, torna-se necessária um equilíbrio entre os conhecimentos distintos, criando um processo de ressignificação, entendido aqui como meio específico de mediar às práticas pedagógicas envolvendo as particularidades de cada povo na formação destes acadêmicos. A partir da efetivação consolidada pela construção de cursos específicos e diferenciados para a formação superior dos professores/as indígenas, as comunidades indígenas se inserem e se apropriam deste espaço para reafirmarem suas lutas políticas frente à sociedade não indígena.

Essas lutas políticas assumem também, o papel representativo do reconhecimento identitário. Segundo Silva (2013, p. 81) a "afirmação da identidade e a enunciação da diferença traduzem o desejo dos diferentes grupos sociais, assimetricamente situados, de garantir o acesso privilegiado aos bens 
sociais".

O texto ora exposto constitui-se na tentativa de discutir o tema da formação indígena intercultural em sua relação com a produção de materiais didáticos específicos no contexto amazônico e das identidades indígenas imersas neste processo. $O$ estudo foi produzido a partir de descrições de situações vivenciadas no âmbito do Curso de Licenciatura em Educação Básica Intercultural da Universidade Federal de Rondônia. Refere-se à análise de um fragmento de etnografia escolar (ANDRÉ, 2005). Busca explorar imagens/representações contidas neste fragmento, elencando as questões da produção de materiais didáticos, currículos e identidades. O desenvolvimento dessa reflexão constitui-se a partir de observações de aulas no curso de formação indígena de Rondônia com a presença das etnias Oro Waram, Oro Nao, Gavião, Arara, Tupari, Suruí e Zoró que, de alguma forma, trouxeram elementos para a discussão.

No primeiro momento, buscamos registrar o que víamos nas aulas, as observações diretas das questões que foram sendo postas, tanto por docentes, como por discentes. Este momento foi inspirado na metodologia do tipo etnográfica em educação (BERGAMASCHI, 2007; WEBER, 2005; ANDRÉ, 2005), que tem o objetivo de capturar, trazer para a grafia aquilo que se institui como fato, como acontecimento no interior da sala de aula, buscando captar olhares, vozes, gestos e sons que versam sobre o tema em estudo, elementos da etnografia que possibilitaram produzir parte dos dados em discussão neste texto. Amparados em André (2005, p. 35) entendemos que "A pesquisa do tipo etnográfico, se caracteriza, fundamentalmente por um contato direto do pesquisador com a situação pesquisada, permite construir os processos, e as relações que configuram a educação escolar cotidiana".

A etnografia aqui pensada também é inspirada na perspectiva pós-moderna, onde etnógrafo/a deve estar atento às questões de subjetividades, que são os modos de conduzir o "eu" para as formas de conhecimentos científicos (BUJES, 2007) e tais modos acarretam reações às formas de poder que produz o sujeito. Para as observações etnográficas é necessário, além do olhar, que o etnógrafo tenha sempre consigo o "Diário de Campo". Trata-se da construção de um diário (caderno, bloco de anotações e/ou outros), onde se anota sistematicamente os elementos observados, as indagações, as possíveis respostas e o "todo" observado. Amplamente utilizado em pesquisas qualitativas, o caderno de campo, torna-se um importante instrumento para a produção dos dados na pesquisa empírica. A pesquisa empírica à qual nos referimos é a participação direta do investigador no âmbito do grupo pesquisado, no caso, o grupo de estudantes indígenas . 
Ao fazer uso dessa estratégia foi possível "reunir elementos e informações na direção de compreender e problematizar aspectos relacionados às formas de negociar, socializar-se, aprender e resistir" (KLEIN; DAMICO, 2012, p. 82) dos/as estudantes indígenas em formação. Assim, com "óculos" de um etnógrafo contemporâneo é que buscamos produzir os dados aqui postos. Vale ressaltar que, o que chamamos de etnógrafo contemporâneo é o que Caldeira, citada por Klein; Damico, (2012, p. 75) e Andrade (2012, p. 183) chamam de "antropólogo contemporâneo". O antropólogo contemporâneo é aquele que se interroga "sobre os limites da sua capacidade de conhecer o outro" (CALDEIRA apud KLEIN; DAMICO, 2012, p. 75) e "procura expor no texto as suas dúvidas e o caminho que o levou à interpretação, sempre parcial" (CALDEIRA apud ANDRADE, 2012, p. 183).

\section{Interculturalidade, materiais didáticos, povos indígenas e a escola}

Durante as etapas de formação do Curso de Licenciatura em Educação Básica Intercultural no ano de 2017, estivemos em observação em disciplinas que contemplavam discussões a respeito da produção de materiais didáticos com o propósito de verificar o processo de formação de professores/as indígenas de Rondônia e Noroeste de Mato Grosso na Universidade Federal de Rondônia - UNIR, no Campus de Ji-Paraná. Tal observação teve como pressuposto investigar os princípios que orientam a formação intercultural levando em consideração as discussões presentes na disciplina intitulada: "Didática Intercultural: processos de ensinar e aprender".

A produção de materiais didáticos específicos e diferenciados para a educação escolar indígena de qualidade é um desafio que a Comissão Nacional de Apoio e Produção de Material Didático Indígena (CAPEMA), segundo Henriques et all (2007, p. 55), tem enfrentado no Brasil desde sua criação por meio da Portaria № 13 do Ministério da Educação e Secretaria de Educação Continuada, Alfabetização e Diversidade (MEC/SECAD) de 21 de Julho de 2005, com objetivo de "qualificar essa ação, proporcionar a participação de diferentes atores envolvidos com a temática com a garantia de representação paritária para o segmento indígena".

Inúmeras foram as ações e documentos que evidenciaram garantias para que os povos indígenas pudessem ter em suas escolas, elementos empregados nas práticas de ensino que caracterizassem suas histórias, saberes, memórias e formas específicas de compreenderem o mundo. É nesta linha de pensamento que o Referencial Curricular Nacional para as Escolas Indígenas, 
argumenta sobre a necessidade de

[...] reconhecer e manter a diversidade cultural e linguística; promover uma situação de comunicação entre experiências socioculturais, linguísticas e históricas diferentes, não considerando uma cultura superior à outra; estimular o entendimento $\mathrm{e}$ o respeito entre seres humanos de identidades étnicas diferentes [...] (RCNEI, 1998, p. 24).

Analisamos que o RCNEI dispõe sobre garantias às populações indígenas no que se refere ao acesso às informações, aos conhecimentos técnicos e científicos da sociedade não indígenas, garantindo também as especificidades culturais indígenas no processo de escolarização. Aliada a esta compreensão, Neves (2009) mostra que a LDB/1996 também considera que os povos indígenas têm direito à valorização de suas memórias e de suas histórias, têm direito à reafirmação de suas identidades étnicas e a valorização de suas línguas maternas, direitos de reafirmarem suas culturas por meio de seus conhecimentos, bem como direito ao acesso às informações, aos conhecimentos técnicos e científicos das sociedades não indígenas.

A utilização e a produção de materiais específicos e diferenciados na/para educação escolar indígena, encontram-se pautados em legislações que estabelecem os critérios da educação escolar indígena, sendo um desses critérios, o uso e a produção de materiais didáticos voltados para a especificidade cultural tradicional de cada povo. Nestes termos, é importante considerar que as linhas gerais que orientam a educação indígena no Brasil consideram a interculturalidade, a comunidade, a sustentabilidade o bilinguismo, bem como as características identitárias, aspectos relevantes no processo de escolarização (CNE - PARECER 14/1999), portanto, essas também se constituem em características a serem consideradas na produção de materiais didáticos.

Um dos objetivos da formação docente indígena é a autonomia para a elaboração de materiais didáticos diferenciados, pensados e produzidos pelos indígenas em seus respectivos contextos étnicos e culturais, de modo que possam ser compreendidos em tradução dos conteúdos ocidentais, permitindo experiências entre os conhecimentos ocidentalizados e os conhecimentos da tradição indígena. São articulações entre a vivência da aldeia e as experiências advindas de outras culturas. Entendemos a partir do que expõe Sacristán (1998), que os materiais didáticos são capazes de dar um suporte pedagógico aos processos de ensino e aprendizagem, principalmente àqueles relacionados à prática pedagógica, uma vez que os materiais didáticos são vistos como 
"apoio imediato dos professores para tomar decisões quanto à programação de seu ensino" (SACRISTÁN, 1998, p. 150). Tais materiais didáticos, porém, devem estar vinculados ao cotidiano dos grupos que dele fazem uso, caso contrário, os conteúdos estudados podem não despertar a curiosidade e a vontade de aprender, pois, em termos de estratégias de apoio ao ensino nas diversas situações pedagógicas, estes poderão não surtir os efeitos esperados.

Com relação aos materiais didáticos como apoio para as situações de ensino, Cortesão e Stoer (2003) apontam que tais instrumentos são passíveis de recontextualização, o que permite a interpretação de que podem ser traduzidos enquanto processos pedagógicos do saber. Ao utilizar materiais didáticos nas situações pedagógicas de ensino os/as indígenas em formação docente, durante as observações etnográficas, mostraram a preocupação em traduzir os conteúdos ocidentais no sentido de aproximá-los à cultura de seu povo em seus respectivos contextos. Essa preocupação nos remete ao que expõem Cortesão e Stoer (2003), quando afirmam que os docentes em suas práticas pedagógicas procuram

[...] combinar uma recontextualização dos saberes científicos contemplados pelos conteúdos programáticos, aqueles saberes que foram considerados importantes para serem transmitidos e, simultaneamente, fazem uma interpretação de finalidades, de metodologias, que constam do projeto curricular, tendo também em atenção, os ritos de aprendizagem que se esperam normalmente dos alunos (CORTESÃO; STOER, 2003, p. 200).

A recontextualização do uso dos materiais didáticos proposta por Cortesão e Stoer (2003) nos permite refletir sobre a educação indígena e a necessidade de produzir materiais didáticos que deem conta de uma educação escolar indígena específica e diferenciada e nos aproximam do conceito de negociação produzidos pelas culturas. A negociação ocorre em meio ao processo de tradução e "transferência de sentido", pois, "cada objetivo é construído sobre o traço daquela perspectiva que ele rasura" (BHABHA, 2013, p. 53). Compreendendo tais prerrogativas, buscamos problematizar a constituição de momentos vivenciados por acadêmicos/as/professores/as indígenas que apontavam para a necessidade de produção de materiais didáticos que em seu bojo, não fossem uma simplificada tradução do mundo colonialista, mas que contivessem saberes negociados em sintonia com os universos indígenas. Assim, apresentamos fragmentos das observações registradas durante os o período de produção de dados, problematizando seu conteúdo a partir de uma 
literatura que compreendemos ser pertinente para estas análises.

\section{Os fragmentos de olhares, as discussões e os resultados}

Considerando a problemática de investigação apresentada, isto é, os desafios da produção de materiais didáticos na formação superior indígena na Amazônia brasileira, buscamos apresentar registros com características etnográficas, para posteriormente problematizar as discussões registradas a partir de diálogos com os/as estudantes indígenas. Neste sentido, expomos a seguir, uma parte do diário de campo produzido em função da busca de entendimentos a respeito da formação indígena no contexto universitário. Trata-se de observações que possivelmente nos indique caminhos para refletir sobre a formação de professores/as indígenas balizados pela perspectiva etnográfica, uma experiência que achamos ser oportuno compartilhar.

\section{Fragmento de registro etnográfico:}

[...] o que é didática? Indagou o professor que ministrava a disciplina. Em resposta, alguns alunos elencaram as seguintes observações que foram sendo registradas no quadro de vidro: - são formas de ensinar, fala um acadêmico indígena. Em seguida ouve-se uma voz que ecoa do fundo da sala: -domínio de conteúdo. De repente o professor fica em silêncio. Alguns alunos murmuram coisas que não é possível entender, até que alguém acrescenta: processo de aprender. Em seguida outro diz: - é conhecimento, saber ensinar. Momento depois se ouve ainda: - experiência do professor e ferramentas de ensino. O professor continuou registrando no quadro, ainda, seguidamente, foi acrescentando à lista, as observações ditadas: - padrão de conhecimento do professor; formas de instrução de como deve ser aplicado o conhecimento. Finalizando a dinâmica, uma acadêmica sugere: - organização do trabalho pedagógico. Frenteaos apontamentos dos alunos o professor inicia uma problematização sobre didática a partir das contribuições dos acadêmicos e das acadêmicas [...] mediante as diversas problematizações efetivadas na aula, de repente ouve-se uma voz que indaga diretamente o professor: - Qual a semelhança ou diferença entre didática e material didático? E continua a 
voz: - se não houvesse materiais didáticos a educação escolar seria possível? Diante dos questionamentos o professor, após pensar por alguns instantes inicia uma explicação sobre a questão e , faz uma analogia entre educação formal e educação não formal. O professor explica que a educação não formal caracteriza-se, principalmente, pela oralidade, pelo caráter espontâneo com que os indivíduos de um grupo se organizam, que possibilitam práticas de ensinar e aprender que podem ser através de exercícios cotidianos, que envolvem afazeres domésticos, narração de histórias dos mais velhos, trocas de experiências entre crianças, jovens e velhos, e as produções de saberes que envolvem toda a dinâmica social e cultural. Neste momento um dos acadêmicos indígenas interrompe por um instante a explicação do professor $e$ fala: - "se a gente não cuidar, nós vamos perder tudo isso. É preciso registrar, filmar, se não, não chega vinte anos pra se acabar". Mediante esta fala o professor elenca o seguinte questionamento: "de que forma a escola indígena pode contribuir para registrar a memória do seu povo? Houve um profundo silêncio, expressões de preocupação abateram sobre os indígenas, podia-se ver nas faces, nos olhares que se cruzavam, no próprio silêncio retumbante que tomou conta da sala por instantes. O silêncio foi rompido, os olhares se direcionaram para um indígena que pronunciou: - "na minha aldeia tem os mais velhos que contam as histórias, mas os mais jovens não tem interesse em aprender. Nós, acadêmicos do intercultural precisamos começar a registrar nossas histórias. Não dá mais para esperar". (Diário de campo, 2017).

O fragmento exposto nos leva a múltiplas direções, neste caso, atentamos para as possibilidades de compreender a articulação dos discursos dos/ das acadêmicos/as aos temas que vinculavam a escola aos materiais didáticos e às identidades que, a nosso ver, cruzam estas composições. Este fragmento de vivências de pesquisa, pedaço de uma etnografia, observação de aula, sugere que os/as acadêmicos/as indígenas presentes naquela aula possuíam uma ideia de didática, possivelmente advindas dos processos de formação que passaram em nível de magistério e, talvez, porque são também professores em suas respectivas comunidades. Todavia, os argumentos daqueles estudantes 
mostram certa confusão sobre o conceito de didática e de materiais didáticos. As enunciações dos acadêmicos se aproximavam da ideia de que "didática é uma área de aplicação da pedagogia, cujo objetivo fundamental é ocupar-se do estudo da organização e direção de situações de aprendizagem. Isso implica no estudo de estratégias de ensino, questões relativas a metodologias de ensino situado em um espaço educativo" (SILVA; GIORDANI, 2009, p. 89).

Entretanto, os registros mostram que, apesar dos/as acadêmicos/as terem em um primeiro momento afirmado elementos que se aproximavam da definição clássica de didática, percebemos seguidamente, a partir das mesmas observações, uma fragilidade em seus saberes ao diferenciar a didática enquanto métodos-técnicas, dos materiais de ensino - elementos didáticos como, livros, vídeos, sons, jogos e outros materiais que podem se tornar didáticos a partir da bricolagem construída pelo professor.

Observamos pelas falas e indagações dos/as acadêmicos/as o fato de que existe uma ausência de materiais didáticos específicos traduzidos em livros e outros artefatos interculturais que podem ser aplicados à prática de ensino em suas escolas nas aldeias. Tais observações nos levam a pensar juntamente com Moreira e Silva (2005) de que esta ausência implica no estabelecimento de uma situação complexa, já que, ao serem escolarizados a partir de matrizes de saberes que não correspondem as expectativas sociais e culturais que possuem, estes sujeitos se produzem a partir de elementos que "desconhecem", se fabricam em campos de significação que não compreendem por completo os significados. Assim, é importante problematizar a ideia de currículo, já que se pensa este artefato escolar como "[...] implicado em relações de poder" (MOREIRA; SILVA, 2005, p. 8) em construção, que carrega visões de mundo, cujos significados pertencem às esferas que os produziu, implicando pensar o currículo como "um terreno central dessa luta" (Idem, p. 30).

A partir dos registros, podemos pensar que o currículo enquanto tecnologia de produção de sujeitos não é um elemento neutro nesta produção, pois possibilita a disposição de saberes que constroem subjetivamente estes sujeitos. Ao incorporar e se "acomodar" como tecnologia exclusivamente escolar, o currículo possibilita que estes sujeitos produzam as experiências de si a partir da "apropriação" das supostas verdades dos saberes postos na escola e, "[...] ao tornarem-se sujeitos de uma determinada verdade, o indivíduo opera sobre si mesmo uma série de transformação no modo de viver" (BERNARDES; GUARESHI, 2007, p. 152).

Outro fator que as observações parecem mostrar refere-se à ideia de que as culturas indígenas estão sendo rapidamente ressignificadas e, apesar 
das relações multitemporais, multiespaciais, que estes grupos acessam após 0 processo de colonização, ainda existem muitas práticas tradicionais indígenas em funcionamento nestas etnias que devem ser registradas e discutidas, pois, as ausências destas problematizações podem, segundo os/as acadêmicos/as, não serem feitas em tempo de se escrever estes conhecimentos, já que muitos velhos estão morrendo e levando consigo um patrimônio cultural inestimável.

O posicionamento destes/as acadêmicos/as indica que muitos destes povos, advêm de processos orais, cujos velhos seriam fontes de saberes que ainda não sãoconhecidos pelos mais jovens, isso nos faz perceber que "a tradição oral designa a arte da palavra numa sociedade, ou mais exatamente, nos grupos sociais que desconhecem a escrita como meio de transmissão do saber. Nesta acepção, a tradição oral engloba a poesia, as baladas, os provérbios, os mitos, os contos e toda a literatura oral" (BESSA FREIRE, 1992, p, 19). O mesmo autor, ao refletir sobre o processo de construção do conhecimento em sociedades ágrafas, mostra que a oralidade para muitos destes grupos étnicos,

[...] é geradora e formadora de um tipo particular de homem e de sociedade. Ali, onde ela não convive com a escrita, acaba modelando a noção de tempo, de espaço, de causa e até mesmo de verdade histórica, que está estreitamente ligada à fidelidade do registro oral e à sua credibilidade (BESSA FREIRE, 1992, p. 19).

Os registros sugerem um processo conflituoso de identidades, os argumentos que pudemos observar, caracterizam estas identidades a partir de marcadores que as definem no conjunto das múltiplas relações estabelecidas pelos sujeitos, dando entender que estes sujeitos pensam estas identidades como essencialidades. Quando se diz: "se a gente não cuidar, nós vamos perder tudo isso. É preciso registrar, filmar se não, não chega vinte anos para se acabar", remete a ideia de que a identidade é algo que pode ser cuidada, ser preservada, possui no ideário comum, certas propriedades que podem ser mantidas, que no conjunto definem e caracterizam posições signas dentro de um campo específico de significação e que, interpelam os sujeitos a assumirem estas identidades, podendo ser esses os elementos a serem priorizados na confecção dos materiais didáticos. Compreendemos, a partir de Quijano (1992) que,

A questão da identidade foi estabelecida na América Latina desde a violenta destruição das sociedades/culturas aborígenes pelos invasores europeus. Sobre os escombros daquelas sociedades e sobre a população sobrevivente, os conquistadores impuseram 
sua dominação colonial, e foi dessa matriz que emergiu uma nova sociedade colonial, a qual logo obteve sua independência política, sem que isso implicasse semelhante descolonização das relações de poder dessa sociedade (QUIJANO, 1992, p. 74).

Entendemos que as lembranças de um passado hostil, de enfrentamentos, produziram o permanente contato de uma identidade do passado em contraponto a uma identidade não originária, herdada dos processos coloniais. Para estes sujeitos, as identidades seriam construídas e fixadas no passado poderia ser preservada e assumida a qualquer tempo. Por outro lado, é possível que, as posições discursivas dos sujeitos, indiquem a existência de conflitos identitários que interpelam estes sujeitos na produção de si para além da fixação, isso mostra que são múltiplos os espaços - significados que são assumidos por estes sujeitos, apontam para a necessidade de examinar os processos pelos quais se formam e se alteram os fragmentos "[...] processos que estão envolvidos relações de poder, ou seja, relações que procuram impor determinados significados (e não quaisquer outros). É como resultado deste processo que se estabelecem as identidades" (VEIGA-NETO, 2004, p. 56).

Tais argumentos nos levam a perceber que, ao falar de uma identidade que se perde, o sujeito reconhece sua transitoriedade e indica que algo ameaça o "núcleo" narrativo dos discursos que alimentam suas subjetividades. Ao propor as soluções para se garantir que tais discursividades sejam perpetuadas, estes sujeitos parecem sugerir que existem essências nestas identidades. Podemos compreender esta posição a partir de Batalla (1988), que ao produzir a teoria do controle cultural, propõe a ideia de que determinados grupos exercem vigilância sobre signos e significados que os caracterizam num campo de significação/diferenciação, assim, estes grupos estabelecem controle sobre a cultura autônoma e tomam

lãs decisiones sobre elementos culturales que son propios porque los produce o porque los conserva como patrimonio preexistente. La autonomía de este campo de la cultura consiste precisamente en que no hay dependencia externa em relación a los elementos culturales sobre los que se ejerce control (BATALLA, 1988, p. 7).

Mostra a crença de que é possível abstrair a cultura para além das relações sociais, das práticas cotidianas. Ao ser captado por técnicas modernas, se diz que os elementos da cultura são permanentemente preservados, retomando a idéia de que, estando lá, nestes instrumentos de registros - textos 
escritos, vídeos, músicas em CDs, essas identidades podem ser assumidas, mesmo que não seja mais possível a transmissão oral destes saberes nas práticas "normais" de trocas de conhecimento na vida diária.

A ideia de que essas identidades podem acabar parece indicar para esses sujeitos que não há possibilidade de ressignificar os elementos da cultura, elas (as identidades) são "trocadas", transformadas, descaracterizando-se por completa, sugerindo a ideia de que existe uma identidade indígena externa, exógena a qualquer outra identidade e que talvez, seja esta identidade que está se perdendo. Alimenta-se uma imagem de identidade iconográfica, pela qual parece que não se vive por completo nas práticas do presente, mas ainda se vive na memória. Assim, a produção de materiais didáticos poderia prender estas memórias, assegurar a continuidade histórica de certos elementos culturais que, mesmo outros, após intensos processos de transformação, poderiam ser mostrados na escola assegurando principalmente a identidade étnica.

Observamos também a existência de múltiplas relações e conflitos de identidades que são assumidas pelos sujeitos. Existe um processo subjetivo destes indígenas que são construídos em relações distintas - tempo/espaço local x tempo-espaço global (HALL, 2011). Os sujeitos construídos em tempos passados não compreendem os significados pelos quais os muitos jovens vêm assumindo certas identidades. Indica que estes jovens estão vivenciando uma estrutura da colonialidade para "deixarem" uma suposta identidade indígena genealógica e assumirem uma identidade vinculada à ideia de modernidade. Sugere que dado o processo de relações diárias com o outro, o não indígena, principalmente pelas constantes visitas aos espaços urbanos, estas identidades encontram menos resistência para interpelar estes jovens.

Muitas destas interpelações podem estar relacionadas à incidência das tecnologias na construção subjetiva dos sujeitos, que podem contribuir para arquitetar os sentidos de si, principalmente a partir das suas experiências com a constituição visual do mundo moderno. Neste contexto, "a mídia ganha, na contemporaneidade um espaço cada vez mais amplo de produção de sentidos e sujeitos por meios de tecnologias de controle" (BERNARDES; GUARESHI, 2007, p. 153), que ao incidir o processo de controle dos sujeitos, formata os gostos, as preferências, a imaginação e os sentidos que vão caracterizando suas identidades.

A relação destes jovens com as sociedades não indígenas pode indicar a postura identitária liquefeita, em que, tomam para si, inúmeras identidades na medida em que elas estão disponíveis para serem assumidas, descartando estas posições ao tempo em que atualizam suas informações sobre o que é a 
"moda". Ao "assumirem" estas identidades em suas múltiplas formas, estes sujeitos articulam as estratégias que os fazem integrar a cultura não indígena, tornando-os invisíveis para adentrar o espaço cultural do outro, sentindo "pouca resistência" a uma "homogeneização" temporária.

Isso pode indicar que muitos indígenas, estrategicamente se articulam com estes espaços outros, a partir da mímica, que pode ser entendida "como a camuflagem, não uma harmonização ou repressão da diferença, mas uma forma de semelhança que difere da presença e a defende, expondo-a em parte" (BHABHA, 2013, p. 135). Assim, em contextos múltiplos, o indígena se apresenta como outro, sem, contudo, deixar de ser o mesmo, uma dupla presença que o acompanha, sem saber ele mesmo produzir a diferenciação do duplo. $O$ duplo que o constrói, articulando o si para além de si, constitui-se como uma armadilha colonial que o faz querer o "ser" do outro em si. É por isso que ao evidenciar os processos de transformações de suas culturas, se diz que "os mais jovens não têm interesse".

Neste sentido, o fragmento nos indica que "as escolas enfrentam, entretanto, desafios a serem superados, de múltiplas dimensões, tais como, a ressignificação da função da escola, do papel do professor, das relações com a comunidade [...]" (MORAES; BUYTENDORP, 2011, p. 33) e dos saberes que subjetivamente vão construindo estes sujeitos. Como argumenta as autoras já referenciadas, é imprescindível “[...] organizar e estruturar os conhecimentos selecionados para a promoção de uma educação que represente o ideal aspirado por uma sociedade num tempo e espaço determinado" (MORAES; BUYTENDORP, 2011, p. 33).

O fragmento mostra também, a urgente necessidade de se construir materiais didáticos específicos e diferenciados para as escolas indígenas de Rondônia. Percebemos, em inúmeras falas de acadêmicos/as, as diversas problemáticas que os povos indígenas enfrentam para produzir uma educação intercultural, bem como, os materiais que alimentariam tal produção. Esses elementos impõem pensar a urgente necessidade de uma ação decolonial, na medida em que a produção de materiais didáticos específicos para as escolas indígenas acena para mudanças estruturais que certamente mexeria com a matriz colonial de poder. Tomamos como decolonialidade a ideia que objetiva

[...] problematizar a manutenção das condições colonizadas da
epistemologia, buscando a emancipação absoluta de todos os ti-
pos de opressão e dominação, ao articular interdisciplinarmente
cultura, política e economia de maneira a construir um campo
totalmente inovador de pensamento que privilegie os elementos 
epistêmicos locais em detrimento dos legados impostos pela situação colonial (REIS; ANDRADE, 2018, p. 3).

Entendemos que, muitos dos povos indígenas vivem na fronteira, entre suas narrativas de tradição e aquela do presente. Todo esse processo gera representações que podem ser assumidas e descartadas, isso porque "[...] é nessas fronteiras, marcadas pela diferença colonial, que atua a colonialidade do poder, bem como é dessas fronteiras que pode emergir o pensamento de fronteira como projeto decolonial" (BERNARDINO-COSTA; GROSFOGUEL, 2016, p. 18).

Dentre os dilemas apresentados destacamos os seguintes pontos que foram possíveis perceber a partir das discussões, como sendo posicionamentos quase que unânime do grupo observado e que foram dispostos em pontos que diretamente se relacionam aos impactos que a ausência de materiais didáticos específicos produzem nas escolas indígenas, pois afetam o planejamento e o trabalho do/as professor/as. Dificuldades dos/das professores/as em colocar em práticas as aprendizagens construídas no âmbito dos cursos de formação, básico, superior ou continuado.

Outro elemento a ser considerado referiu-se a proposição que incide sobre as ausências de conhecimentos de suas culturas por parte dos/das professores/as indígenas que participaram da investigação, o que, possivelmente afeta a construção dos Projetos Políticos Pedagógicos das escolas, provocando certa perda de direcionamento na educação escolar.

As não concretizações de materiais específicos para as escolas adensam a falta de conhecimentos tradicionais acerca dos temas a serem trabalhados, principalmente nos anos iniciais de formação, o que caracteriza a falta de um currículo diferenciado, fragilizando a postura decolonial que a educação escolar indígena vem assumindo.

\section{Observações Finais}

A apropriação dos conhecimentos universais pelos povos indígenas é um direito garantido pelas legislações educacionais brasileiras, e tais garantias expressam a difícil articulação destes conhecimentos com os saberes locais, principalmente na construção e elaboração de materiais didáticos específicos para as escolas indígenas.

Tais compreensões indicam que estes materiais didáticos devem ser formulados em consonância com os saberes e tradições indígenas e não indígenas, de modo que permitam a reflexão, tanto sobre a sociedade nacional, 
global, como sobre as próprias culturas e os processos próprios de aprendizagem destas comunidades. A ideia de que as culturas indígenas estão sendo ressignificadas nos remete a um entendimento de que estas populações estão se apropriando de conhecimentos e informações que historicamente não pertencem as suas matrizes culturais, e isso produz inúmeras possibilidades de apropriação de identidades. Essas identidades vão sendo redefinidas, transformadas, descaracterizando-se, recaracterizando-se. Assim, a produção de materiais didáticos específicos e diferenciados assegura a continuidade histórica de certos elementos culturais e, mesmo com intensos processos de transformação cultural, podem ser trabalhados na escola assegurando principalmente a identidade étnica destes povos.

Os registros de observação etnográfica nos levam a compreender as múltiplas direções dos discursos dos/as acadêmicos/as, principalmente quando os mesmos voltam suas falas para a necessidade de ampliar os saberes a respeito dos processos próprios de aprendizagem vinculados à escola indígena e, as possibilidades de produção de materiais didáticos ligados a certas posições de identidades que cruzam suas culturas. Durante as diversas problematizações que já expomos, percebemos que se faz urgente construir materiais didáticos específicos e diferenciados para as escolas indígenas de Rondônia. Entretanto, vale ressaltar que são muitas as dificuldades de se implementar a produção desses materiais no âmbito das comunidades indígenas.

Considerando as afirmativas postas, entendemos que a produção de materiais específicos e diferenciados para a educação escolar indígena pode se tornar um instrumento didático capaz de dar sustentação às políticas surgidas em favor da educação escolar indígena num contexto intercultural, desde que os docentes indígenas possuam autonomia com relação à produção e à aplicação desses materiais dentro de suas comunidades, de modo que tais materiais sirvam de apoio para suas práticas pedagógicas e curriculares.

\section{Referências}

AGULERA URQUIZA, Antônio Hilário; NASCIMENTO, Adir Casaro. O desafio da interculturalidade na formação de professores indígenas. Espaço Ameríndio, Porto Alegre, V.4, n. 01, p.44-60, Jan/Jun. 2010.

ANDRADE, Sandra dos Santos. A entrevista narrativa ressignificada nas pesquisas educacionais. In: MEYER, Dagmar Estermann.; PARAÍsO, Marlucy Alves. Metodologias de pesquisas pós-críticas em educação. Belo Horizonte: Mazza edições, 2012. 
ANDRÈ, Marli Eliza D.A de. Etnografia na prática escolar. 12. Ed. Campinas: Papirus, 2005.

BATALLA, Guillermo Bonfil. La teoria delcontrol cultural em el estúdio de processos étnicos. Anuário Antropológico/86 (Editora Universidade de Brasilia/ Tempo Brasileiro) 1988: 13-53.

BERGAMASCHI, Maria Aparecida. Educação Escolar Indígena: um modo próprio de recriar a escola nas aldeias Guarani. Cad. Cedes, Campinas, vol. 27, n. 72, p. 197- 213, maio/ago. 2007.

BERNARDINO-COSTA, Joaze; GROSFOGUEL, Ramón. Decolonialidade e perspectiva negra. Revista Sociedade e Estado - Volume 31 Número 1 Janeiro/ Abril 2016.

BERNATES, Anita Guazzelli; GUARESCHI, Neuza. Estratégias de Produção de Si e Biotecnologias. Psicologia em Estudos, Maringá, v. 12, n. 1, p. 151-159, Jan/ Abri. 2007.

BESSA FREIRE, José Ribamar. A canoa do tempo, tradição oral e memória indígena. In: Salomão, Jayme (Org): América: Descoberta ou Invenção. 40 Colóquio UERJ. Rio de Janeiro, Imago, 1992.

BHABHA, Homi, K. O Local da Cultura. Belo Horizonte: Ed. UFMG, 2013.

BUJES, Maria Isabel Edelweiss. Descaminhos. In: COSTA, Marisa Vorraber (Org.). Caminhos Investigativos II: outros modos de pensar e fazer pesquisa em educação. Rio de Janeito: lamparina, 2007.

BRASIL. Ministério da Educação - MEC. Lei de Diretrizes e Bases da Educação Nacional - LDB 1996 Disponível em: http://www.planalto.gov.br/ccivil_03/ Leis/L9394.htm Acessado em: 24 de dezembro de 2020.

BRASIL. Ministério da Educação - MEC. Secretaria de Educação Fundamental. Referencial curricular nacional para as escolas indígenas. Ministério da Educação e do Desporto, Secretaria de Educação Fundamental. - Brasília: MEC/ SEF, 1998.

BRASIL. Ministério da Educação - MEC Conselho Nacional de Educação Básica- CEB/CNE. Parecer CNE № 14/99. Disponível em: http://portal.mec.gov. br/docman/marco-2012-pdf/10204-13-parecer-cne-ceb-14-99-diretrizes-curriculares-nacionais-da-educacao-escolar-indigena/file Acessado em: 30 de dezembro de 2020. 
CASTRO GÓMEZ, Santiago. Decolonizar la universidad. La hybris del punto cero y el diálogo de saberes. In: CASTRO GÓMEZ, Santiago y GROSFOGUEL, Ramón. El giro decolonial: Reflexiones para una diversidad epistémica más allá del capitalismo global. Colombia: Siglo del Hombre Editores, 2007.

CORTESÃO, Luiza; STOER, Sthephen R. A interface da educação intercultural e a gestão da diversidade na sala de aula. IN: GARCIA, Regina Leite; MOREIRA, Antonio Flávio. Currículo na contemporaneidade. São Paulo: Cortez, 2003, p. 189-208.

CUSICANQUI, Silvia Rivera. Violencias (re) encubiertas em Bolivia. La Paz: Piedra rota, 2010.

GROSFOGUEL, Ramón. Descolonizando los universalismos occidentales: el pluri-versalismo transmoderno decolonial desde Aimé Césaire hasta los zapatistas. In: CASTRO GÓMEZ, Santiago y GROSFOGUEL, Ramón. El giro decoIonial: Reflexiones para una diversidad epistémica más allá del capitalismo global. Colombia: Siglo del Hombre Editores, 2007.

HALL, Stuart. Da diáspora: identidades e mediações culturais. Belo Horizonte: editora UFMG, 2011.

HENRIQUES, Ricardo; et al. Educação Escolar Indígena: Diversidade sociocultural indígena ressignificando a escola. Cadernos SECAD, Secretaria de Educação Continuada, Alfabetização e Diversidade. Brasília - DF, 2007.

KLEIN, Carin; DAMICO, José. O uso da etnografia pós-moderna para a investigação de políticas públicas de inclusão social. In: MEYER, Dagmar Estermann; PARAÍSO, Marlucy Alves. Metodologias de pesquisas pós-críticas em educação. Belo Horizonte: Mazza edições, 2012.

LANDER, Edgardo. Ciências Sociais: saberes coloniais e eurocêntricos. In: LANDER, Edgardo (org). Colonialidade do Saber, Eurocentrismo de Ciências Sociais: perspectivas latino-americanas. Buenos Aires: Clasco, 2005.

MORAES, Lúcia Ruas Chelotti de; BUYTENDORP, Adriana Aparecida Burato Marques. O currículo multicultural e as práticas expressas nos materiais didáticos. Diálogos Educ R. Campo Grande, Ms, v. 2, n. 2, p. 32-43, Nov, 2011.

MOREIRA, Antonio Flávio; SILVA, Tomaz Tadeu da. Sociologia e Teoria Crítica do Currículo: uma introdução. In: MOREIRA, Antonio Flávio; SILVA, Tomaz Tadeu da. Currículo, Cultura e Sociedade. São Paulo: Cortez, 2005.

NEVES, Josélia Gomes. Universidade e Povos Indígenas: A possibilidade do diálogo intercultural na floresta. AMARAL, Nair Gurgel do. Multiculturalismo na 
Amazônia: O singular e o plural em reflexão e ações. Curitiba: Editora CRV, 2009.

QUIJANO, Anibal. Notas sobre a questão da identidade e nação no Peru. Revista Estudos Avançados. 6 (16), 1992.

QUIJANO, Anibal. Colonialidade do poder, eurocentrismo e América Latina. In: LANDER, Edgardo. Colonialidade do saber, eurocentrismo e ciências sociais: perspectivas latino americanas. Buenos Aires: Clacso, 2005.

REIS, Maurício de Novais; ANDRADE, Marcilea Freitas Ferraz de. O pensamento decolonial: análise, desafios e perspectivas. Revista Espaço Acadêmico, $\mathrm{n}$. 22, 2018. In: http://www.periodicos.uem.br/ojs/index.php/EspacoAcademico/article/view/41070 . Acessado em: Fevereiro de 2018.

SACRISTÁN, José Gimeno. O currículo: uma reflexão sobre a prática. Porto Alegre: Artmed, 1998.

SECCHI, Darci. Autonomia e Protagonismo Indígenas nas Políticas Públicas. Cadernos de Educação Escolar Indígenas - PROESI. (Org) JANUARIO, Elias et all. Barra do Bugres: UNEMAT, v.5, n. 01, 2007.

SILVA, EvellynLedur da; GIORDANI, Estela MAris. Aprendizagens de Professores e Alunos com Materiais Didáticos nos Anos Iniciais do Ensino Fundamental. Anais do IX Congresso Nacional de Educação - EDUCERE, PUCPR, 2009.

SILVA, Tomaz Tadeu da. A produção social da identidade e da diferença. In: SILVA, Tomaz Tadeu da (Org). Identidade e diferença: a perspectiva dos estudos culturais. 12. ed. Petrópolis, RJ: Vozes, 2013.

VEIGA- NETO, Alfredo. Michel Foucault e os Estudos Culturais. In: COSTA, Marisa Vorraber. Estudos Culturais em Educação. Porto Alegre: UFRGS, 2004.

WEBER, Ingrid. Um copo de cultura: os HimiKuin (Kaxinawá) do rio Humaitá e a escola. Rio Branco: Edufac, 2005.

Data de recebimento: 19.08 .2019

Data de aceite: 23.09 .2020 